\title{
Can Market Power influence Employment, Wage Inequality and Growth? *
}

\author{
Alberto Buccił- Fabio Fiorillo $\ddagger$ Stefano Staffolani ${ }^{\S}$
}

3rd November 2000

\begin{abstract}
We introduce an efficiency-wage mechanism into an innovationdriven growth model. Due to informational problems, the labour market is segmented and homogeneous workers may be employed either in a non-competitive intermediate sector or in a competitive research one. We analyse the impact that variations in the monopoly power level may have on unemployment, wage inequality and growth. We find that the lower the product market competition in the intermediate sector, the higher the research employment, the lower the intermediate sector employment, the higher the aggregate growth rate. Growth and inequality are negatively correlated whereas growth and unemployment are positively correlated. The last two results are obtained through numerical simulations.
\end{abstract}

JEL: D43, D92, J41, O3

Keywords: Efficiency wages, Research and Development, Endogenous Growth, Market Power

*We thank Renato Balducci, Riccardo Lucchetti and the participants to the XVth Italian Conference on Labour Economics held in Ancona on the 28th-29th september 2000. The usual disclaimers apply.

${ }^{\dagger}$ Dipartimento di Economia, Universita di Ancona; Universitè Catholique de Louvain, Departement des Sciences Economiques: Albertob@deanovell.unian.it

${ }_{\ddagger}^{\ddagger}$ Dipartimento di Economia, Universita di Ancona: Fabiof@deanovell.unian.it

$\S$ Dipartimento di Economia, Universita di Ancona: Staffolani@deanovell.unian.it 


\section{Introduction}

Endogenous growth models usually assume full employment in the labour market. Empirical evidence on european labour markets does not confirm this hypothesis. Even from a theoretical perspective, labour economists have removed this assumption (Layard, Nickell, Jackmann, 1991). In this respect, models with asymmetric information have proposed many factors potentially able to explain the persistence of an unemployment rate above the frictional one, showing at the same time that labour market segmentation may be another important consequence of informational problems.

However, these analyses, generally known as efficiency wage theories, are usually carried out in a static framework and rarely consider the relationship between unemployment, wage inequality and growth ${ }^{1}$.

Using a research based growth model, in this paper we analyse the consequences of a non competitive labour market on the economic system.

In particular, we propose a growth model in which the labour market displays moral hazard problems due to imperfect monitoring. A natural consequence of this hypothesis is the emergence of unemployment and wage inequality. Labour market is supposed to be of the type described by Shapiro and Stiglitz (1984) modified in order to allow for segmentation as in Perrot and Zylberberg (1989), Cahuc and Zajdela (1991), Fiorillo and Staffolani (2000) and De Palma (2000).

Workers are homogeneous with respect to their productivity and their reservation wage. Segmentation is due to the coexistence of two different sectors: the research sector, characterised by imperfect monitoring of workers effort, and the intermediate goods producers sector, where labour market is competitive $^{2}$. So, wage inequalities that emerge in the labour market depend only on job differences.

The paper is organised as follows. In the second section we propose an analitical description of the labour market outlined above; the third section presents a traditional endogenous growth model based on the existence of a research sector whose aim is to discover new varieties of intermediate goods. The forth section evaluates the relationships among product market competition, growth, unemployment and wage inequality. Some concluding remarks are presented in section 5 .

\footnotetext{
${ }^{1}$ Among the exceptions, notably are: Bean and Pissarides (1993) and the comment of Caballero (1993) to their paper; Aghion e Howitt (1994); Van Schaik and De Groot (1998).

${ }^{2}$ Indeed, dualism in the labour market is treated as exogenous here. Cahuc e Zajdela (1991) considering turnover costs, have endogenised segmentation.
} 


\section{The labour market}

As mentioned above, we suppose that labour relations in the research sector are characterised by the existence of monitoring problems. Workers know that their effort can be monitored with a probability $q$. If monitored, a worker is fired if his effort is below a given level. Indipendently on effort, each worker may be fired for exogenous reasons with probability $b$.

\subsection{The wage rate}

Usually, in efficiency wage models workers utility is separable and linear in wage $(w)$ and effort $(E)$. The use of a separable utility function $(w-E)$ in growth models could give rise to some problems when effort is considered constant.

In fact, with the instantaneous utility function $u=w-E$, the difference $\frac{\dot{u}}{u}-\frac{\dot{w}}{w}>0$ is time dependent. This is not the case if we use an utility function

of the type: $u=\frac{w}{E}$, where $\frac{\dot{u}}{u}=\frac{\dot{w}}{w}$ at each $t$. Hence, using an utility function for the representative worker of the type:

$$
u_{i}=u\left(w_{i}\right)=\frac{w_{i}}{E}
$$

we define with $E=1$ the effort of a shirker worker and with $E>1$ the effort of a non shirker.

Using an asset pricing approach ${ }^{3}$ we first compute worker expected intertemporal utility in both sectors.

The expected intertemporal utility of a non-shirker worker employed in the research sector times the discount rate $\left(\rho U_{N}\right)$ must be equal to the sum of three terms: 1)the instanteneous utility $\left.\left(\frac{w_{N}}{E}\right), 2\right)$ the loss of utility in the case of firing for exogenous reasons $\left(b\left(U_{S}-U_{N}\right)\right)$, 3) the variation in utility $\left(\dot{U}_{N}\right)$ during the time interval $d t$. Therefore:

$$
\rho U_{N}=\frac{w_{N}}{E}-b\left(U_{N}-U_{S}\right)+\dot{U}_{N}
$$

where $U_{S}$ is the expected intertemporal utility of a worker employed in the intermediate sector.

The utility of a shirker worker employed in the same sector is:

$$
\rho U_{N}^{s}=w_{N}-(b+q)\left(U_{N}^{s}-U_{S}\right)+\dot{U_{N}^{s}} .
$$

\footnotetext{
${ }^{3}$ As in the recent work of Mendez 1999.
} 
Unlike the previous case, since a worker may be monitored and fired with probability $q$, the probability to be fired is given by $(b+q)$.

The discounted expected intertemporal utility of a worker employed in the intermediate sector $\left(\rho U_{S}\right)$ is:

$$
\rho U_{S}=\frac{w_{S}}{E}+a_{S}\left(U_{N}-U_{S}\right)+\dot{U}_{S}
$$

where $a_{S}$ is the probability to be hired in the research sector and $\left(U_{N}-U_{S}\right)$ represent the higher utility he would obtain.

Finally, the discounted expected intertemporal utility of an unemployed $\left(\rho U_{D}\right)$ is:

$$
\rho U_{D}=R+a_{D}\left(U_{N}-U_{D}\right)+\dot{U_{D}},
$$

where $R$ is the reservation wage and $a_{D}$ is the probability to be hired in the research sector. Given that labour market in the intermediate sector is competitive, we must have: $U_{D}=U_{S}$.

We assume that workers in the intermediate sector and unemployed people have the some probability to find a job in the research sector. Under this hypothesis, $a_{D}=a_{S}=a$, given Eqs. 4 and 5, we obtain:

$$
w_{S}=E R
$$

Firms in the research sector avoid that their own workers behave as shirkers. In doing so, they have to pay a wage that make the condition $U_{N}=U_{N}^{s}$, checked (this condition implies $\dot{U}_{N}=\dot{U}_{N}^{s}$ ). Combining Eq. 2 and Eq. 3, the following non shirker condition must hold:

$$
w_{N}\left(1-\frac{1}{E}\right)=q\left(U_{N}-U_{S}\right) .
$$

As we will clarify later, the steady state equilibrium is such that: 1) employment in both sectors is stricty positive and costant over time; 2) wages $\left(w_{N}\right.$ and $\left.w_{S}\right)$ as well as expected intertemporal utilities $\left(U_{N}\right.$ and $\left.U_{S}\right)$ in both sectors grow at the same rate $(g)$, that, in equilibrium, will be constant and equal to the total output growth rate. Hence: $g U_{N}=\dot{U}_{N}$ and $g U_{S}=\dot{U}_{S}$.

The difference between Eqs. 2 and 4 gives:

$$
(\rho-g)\left(U_{N}-U_{S}\right)=\frac{w_{N}-w_{S}}{E}-(a+b)\left(U_{N}-U_{S}\right)
$$

and the efficiency wage: 


$$
w_{N}=\frac{w_{S}}{1-(\rho-g+a+b) \frac{E-1}{q}} .
$$

Flows condition in the research sector requires that the number of fired workers is equal to the one of the hired ${ }^{4}$ :

$$
b N=a(1-N)
$$

where the labour force is normalised to 1 . Accordingly, $D+N+S=1$, where $D$ represents both the unemployment rate and the number of the unemployed people. Solving the flows condition above in $a$, substituting the result in Eq. 6 and dividing it by $w_{S}$, we obtain the relative wage setting function $\left(\omega=w_{N} / w_{S}\right)$ :

$$
\omega=\frac{\bar{q}}{\bar{q}-\left(\rho-g+b \frac{1}{1-N}\right)}
$$

where $\bar{q}=\frac{q}{E-1}$.

We can state now the following:

Proposition 1 The ratio between the wage rate of workers in the research sector and the one of workers in the intermediate sector (relative wage) is an increasing function of the employment in the research sector and a decreasing function of the aggregate growth rate $(g)$.

Proposition 1 is proved differentiating Eq. 7 with respect to $N$ and $g$.

Eq. 7 shows that relative wage depends on employment and the growth rate. It is coherent with the traditional efficiency wage models as far as the relationship between relative wages and unemployment is concerned. Instead, the relationship between relative wage and growth rate needs further explanation.

In equilibrium wages in both sectors grow at the same rate and therefore their absolute difference grows over time. This means that the "value" of a job in the primary sector with respect to the outside options is higher when growth rates are higher. The higher the growth rate, more costly is to be fired from a job that pays an efficiency wage. Because of this, workers require a lower efficiency premium. In other words, an economic system that grows faster presents less incentive problems.

\footnotetext{
${ }^{4}$ Given that firms set wages according to Eq. 6, no one will shirk. So, the exit rate is given by $b$.
} 


\section{$2.2 \quad$ Preferences}

In this economy there exists two different types of employed workers. Both those employed in research and in capital goods manufacturing earn a real wage $w_{i}$ ( $i=N$ for the research workers; $i=S$ for the intermediate sector workers) and deliver an effort $E$, which is constant and equal for all workers. The instantaneous utility function has been defined in Eq. 1.

We assume that workers devote all their wage to the purchase and the consumption of the only homogeneous final good. Therefore, $w_{i}=c_{i}, \quad \forall i=$ $S, N$. Under this hypothesis, the instantaneous utility function can be recast as:

$$
u_{i}=u\left(c_{i}\right)=\frac{c_{i}}{E}, \quad i=S, N .
$$

In synthesis, the dynamical problem faced by an infinitely-lived agent reads as:

$$
\begin{gathered}
\underset{\substack{\operatorname{Max} \\
\left\{c_{i, t}\right\}_{t=0}^{\infty}}}{\sin }=\frac{1}{E} \int_{0}^{\infty} e^{-\rho t} c_{i, t} d t \\
W_{i, t}=w_{i, t}+r_{t} W_{i, t}-c_{i, t}
\end{gathered}
$$

where $\rho>0$ denotes the subjective discount rate, $W$ is individual wealth (in real terms) and $r$ the real interest rate. The solution to this dynamical problem is given by the Euler (or Ramsey-Keynes) equation:

$$
r_{t}=\rho=r
$$

As already mentioned above, at this stage it is easy to show that in a steady-state equilibrium (when all variables depending on time, wages included, grow at a constant rate), the expected intertemporal utility of the two classes of employed workers grow at the same rate of their own real wage (and consequently at the same rate of their own consumption and instantaneous utility) $)^{5}$.

\section{Endogenous Growth}

The economic structure we have in mind is qualitatively similar to the one proposed by the traditional "Ideas-Based" growth models (Aghion and Howitt,

\footnotetext{
${ }^{5}$ Indeed $U_{i, t}=\frac{1}{E} \int_{t}^{\infty} e^{-\rho(\tau-t)} w_{i}(\tau) d \tau=\frac{1}{E} \frac{w_{i}(t)}{\rho-g}$, with $\tau>t$ and $\rho>g$. Hence, $\frac{d U_{i, t}}{d t}=$ $\frac{1}{E} \frac{1}{\rho-g} \frac{d w_{i}(t)}{d t}$ and $\frac{\dot{U}_{i, t}}{U_{i, t}}=\frac{\dot{w}_{i, t}}{w_{i, t}}$. This follows immediately from the fact that in steady state $g$ is constant. Finally, the condition $\rho>g$ is necessary for the intertemporal utility function to be positive and bounded.
} 
1992; Grossman and Helpman, 1991, Chaps. 3 and 4; P.Romer, 1990). In particular, we imagine an economy where three sectors of production are vertically integrated. In the research sector, firms use $N$ workers (subject to monitoring activity), together with knowledge capital $(A)$ to engage in innovation activity. Innovation consists in discovering new designs for firms operating in the capital goods sector. The number of designs existing at a certain point in time coincides with the number of intermediates and represents the actual stock of non-rival knowledge capital available in the economy. To enter the intermediate sector, a firm must acquire a patent. Purchasing a patent means that the firm acquires not only the know-how to manufacture a specialised intermediate, but also an infinitely-lived monopolistic position to market the same intermediate good. Unlike Romer (1990), and following Grossman and Helpman (1991, Chap. 3), we assume that local intermediate monopolists employ only workers (not subject to monitoring activity) through a one-to-one technology ${ }^{6}$. Finally, in the final output sector firms produce a homogeneous good combining, at time $t$, all the varieties of intermediate inputs existing at the same time $\left(A_{t}\right)$.

\subsection{The Final Good Sector.}

The economy's aggregate production function for the numeraire final good $(\mathrm{Y})$ is given by:

$$
Y_{t}=\left[\int_{0}^{A_{t}} x_{i t}^{\alpha} d i\right]^{\frac{\gamma}{\alpha}}, \quad \gamma<1, \quad 0<\alpha<1 .
$$

With $\gamma<1$, the CES-type technology in Eq. 9 exhibits decreasing returns in the quantity of the i-th intermediate input employed at time $t$. This hypothesis allows us to define exactly both the optimal level of inputs being used (the different varieties of capital goods) and, as will be clearer later on, the dimension of the economic system under analysis. $A_{t}$ denotes the total number of capital goods invented up to $t$. In this sector atomistic producers engage in perfect competition. A representative firm maximises its own instantaneous profit with respect to $x_{i t}$, taking all prices as given and subject to the following expenditure constraint ${ }^{7}$ :

\footnotetext{
${ }^{6}$ Results do not change if we assume that both types of workers (those who are and those who are not subject to monitoring) are employed in both sectors (intermediate goods and research). This hypothesis has, however, the disadvantage of making the exposition a bit more complicated.

${ }^{7}$ From now on, in order to ease the notation, the index $t$ near the variables depending on time will be omitted, unless this may induce confusion.
} 


$$
\int_{0}^{A}\left(p_{i} x_{i}\right) d i \leq Y
$$

From the zero profit condition ${ }^{8}$ it is possible to derive the (inverse) demand of the downstream sector for the i-th intermediate input:

$$
p_{i}=\frac{Y^{\left(1-\frac{\alpha}{\gamma}\right)}}{x_{i}^{1-\alpha}}
$$

Under the specific assumption that each firm producing intermediate inputs is so small that a marginal increase in the quantity it produces does not change the quantities produced by its own market rivals, and then total intermediate output ${ }^{9}$, from Eqs. 9 and 10 it follows that the demand for the i-th capital good exhibits a price elasticity equal to $\frac{1}{1-\alpha}$. This elasticity coincides with the elasticity of substitution between two generic varieties of intermediates. As we will see in a moment, $\alpha$ also enters into the definition of the mark-up rate charged over the marginal cost by the local intermediate monopolists.

\subsection{The Intermediate Inputs Sector}

Capital goods producers engage in monopolistic competition. Each firm produces one (and only one) horizontally differentiated intermediate good and must purchase a patented design before producing its own specialised capital good. Thus, the price of the patent represents a fixed entry cost. Following Grossman and Helpman (1991, Chap. 3), we assume that each intermediate (local) monopolist has access to the same one-to-one technology employing non-monitored work only:

$$
x_{i}=s_{i} \quad \forall i \epsilon(0, A)
$$

\footnotetext{
${ }^{8}$ Since we are dealing with decreasing returns to scale in a competitive product market, the price of the final good will decrease as long as firms make a positive profit. We suppose the existence of a minimum technical size for firms, that will stop this process at a certaint point in time. Hence, the intersection between the increasing average cost curve and the minimum firm's size defines the price of the final output. We set this price to one, since the final output has been choosen as numeraire.

${ }^{9}$ In other words, as common in this literature, we are assuming that in the intermediate sector there exists no strategic interaction among firms, so that $\frac{\partial Y}{\partial x_{i}}=0$.
} 
The firm producing the i-th variety, after bearing the expenses related to the purchase of the i-th idea, maximises at each point in time its own instantaneous profit function with respect to $x_{i}$ and subject to the demand constraint (10). The solution to this maximisation problem gives the optimal price the i-th intermediate producer sets for one unit of its output:

$$
p_{i}=\frac{Y^{\left(1-\frac{\alpha}{\gamma}\right)}}{x_{i}^{1-\alpha}}=\frac{1}{\alpha} w_{S}=p \quad \forall i \epsilon(0, A) .
$$

Thus, the constant mark-up charged over the marginal cost by each intermediate (local) monopolist $\left(\frac{1}{\alpha}\right)$ turns out to be a function of the price elasticity of the demand faced by the i-th capital good producer (and defined just above). Since the price of one unit of the $i-t h$ intermediate input is equal for each $i$, from Eq. 10 it follows that each local monopolist will produce the same output $(x)$, accruing the same profit rate $(\pi)$. Such a result allows us to rewrite Eqs. 9 and 10 respectively as:

$$
\begin{gathered}
Y=A^{\frac{\gamma}{\alpha}} x^{\gamma} \\
p=\frac{A^{\frac{\gamma}{\alpha}-1}}{x^{1-\gamma}}
\end{gathered}
$$

Defining with $X \equiv A x=S \equiv \int_{0}^{A} s_{i} d i$ the total capital goods ${ }^{10}$ output, we can easily obtain the following two expressions:

$$
\begin{array}{r}
Y=A^{\gamma \phi(\alpha)} X^{\gamma} \\
p=\frac{A^{\gamma \phi(\alpha)}}{X^{1-\gamma}}
\end{array}
$$

where $\phi(\alpha) \equiv \frac{1-\alpha}{\alpha}$ is a proxy of the mark-up rate charged over marginal cost by intermediate firms ${ }^{11}$.

From the last equation above, we can express $S$ as a function of $\gamma$ (the measure of aggregate returns to scale existing in the downstream sector), $\alpha$, $A$ and $w_{s}$ (the wage rate accruing to the workers employed in the intermediate sector):

$$
S=X=\frac{A^{\frac{\gamma}{1-\gamma} \phi(\alpha)}}{p^{\frac{1}{1-\gamma}}}=\left(\frac{\alpha A^{\gamma \phi(\alpha)}}{w_{S}}\right)^{\frac{1}{1-\gamma}}
$$

\footnotetext{
${ }^{10}$ Recall that these are available at time $t$ in $A$ varieties.

${ }^{11}$ See Benassy, 1998 on this point.
} 
As is clear from Eq. 13, the demand for non-monitored workers $(S)$ depends positively on the inverse of the mark-up term $(\alpha)$ and negatively on the wage rate $\left(w_{S}\right)$. Finally, the profit of a generic capital goods producer will be equal to:

$$
\pi=p x-w_{S} x=(1-\alpha) p x=\phi(\alpha) \frac{w_{S} S}{A} .
$$

Given the intermediate sector market structure, such a profit is to be decreasing with respect to the number of intermediate firms $(A)$. From Eq. 14 , it is possible to show that this is true whenever $\gamma<\alpha$. From now on we will assume that such a condition is always checked.

\subsection{The R\&D Sector}

There are many competitive firms undertaking R\&D These firms produce designs (or blueprints) indexed by 0 through an upper bound $A \geq 0$. Thus, $A$ measures the total stock of society's knowledge. Designs are patented and partially excludable, but nonrival and indispensable for capital goods production. With access to the stock of knowledge $A$, in order to develop new blueprints, research firms use monitored workers $(N)$. These workers are paid an efficiency wage $w_{N}$. Following P. Romer (1990) and Grossman and Helpman (1991, Chap.3), the production function of new designs is governed by:

$$
\dot{A}=\mu N A
$$

where $\mu>0$ is the productivity parameter of the research workers .

Since the sector is competitive, entry of new firms into the sector will happen until the profit possibilities will be completely exhausted. The static free entry condition amounts to set:

$$
P_{A}=\frac{w_{N}}{\mu A}
$$

Eq. 16 simply represents the equilibrium condition prevailing in a perfect competition market (namely the equality between price and marginal cost).

\subsection{Steady-State Analysis.}

We concentrate on an equilibrium characterised by the coexistence of both the intermediate and research sectors. In other words, in the present paragraph we compute the growth and wage inequality rates of the economy when 
employment in the two above mentioned sectors (respectively $S$ and $N$ ) is positive and the growth rates of all the variables depending on time are constant (balanced growth path). In what follows, we denote by $g_{x}$ the growth rate of variable $x$. From Eq. 15, the growth rate of technology is $g_{A}=\mu N$, which is constant when $N$ is constant $\left(g_{N}=0\right)$. In addition, $g_{N}$ will be positive when $N>0$. Along a balanced growth path (when $g_{S}$ is constant), $S$ will be constant as well $\left(g_{S}=0\right)$. This result stems from the following observation: 1)if $g_{S}<0$, then the intermediate sector shrinks over time and in the very long run(when $t \rightarrow \infty$ ) it disappears completely ( $S$ tends to zero asymptotically). 2)if $g_{S}>0$, then the resource constraint ( $1 \geq S$, where 1 is the constant normalised labour force) is not checked anymore when $t$ gets infinitely large.

With $S$ constant, from Eq. 13 the ratio $\frac{A^{\gamma \phi(\alpha)}}{w_{S}}$ is constant as well and

$$
g_{w_{S}}=\gamma \phi(\alpha) g_{A}
$$

In order to simplify the notation, we define:

$$
G(\alpha) \equiv \frac{A_{t}^{\gamma \phi(\alpha)}}{w_{S_{t}}}=\frac{A_{0}^{\gamma \phi(\alpha)}}{w_{S_{0}}}, \quad \forall t
$$

and suppose that $A_{0}$ (the number of capital goods varieties existing at time $t=0$ ) be equal to one. In such a case $G$ becomes a parameter not depending on $\alpha$, since it is equal to: $G=\frac{1}{w_{S_{0}}}=\frac{1}{E R_{0}}$. Then:

$$
S=(\alpha G)^{\frac{1}{1-\gamma}}
$$

For given $A$, total final output can be written as:

$$
Y=\left(\frac{\alpha A^{\phi(\alpha)}}{w_{S}}\right)^{\frac{\gamma}{1-\gamma}}
$$

Taking logs and deriving with respect to time both sides of Eq. 19, the growth rate of output is:

$$
g_{Y}=\gamma \phi(\alpha) g_{A}
$$

In order to reach this result we have used Eq. 17. From Eqs. 19 and 20 together, we conclude that $g_{Y}=g_{w_{S}}$. In order to compute the growth rate of $w_{N}$ (the wage rate accruing to the research workers) we use an "asset pricing 
equation" approach. According to such approach, the price (or market value) of a generic patent (idea) at time $t\left(P_{A}\right)$ will be:

$$
r P_{A}=\pi+\dot{P}_{A}
$$

Eq. 21 simply suggests that the interest on the value of the i-th idea $\left(r P_{A}\right)$ must be equal, in equilibrium, to the sum of two terms: 1)the instantaneous monopoly profit coming from the production of the i-th capital good $(\pi) ; 2)$ the capital gain or loss matured on $P_{A}$ during the time interval $d t\left(\dot{P}_{A}\right)$.

From Eq. 21, using the corresponding equations for $P_{A}$ (Eq. 16) and $\pi$ (Eq. 14) and the fact that $r=\rho$ (Eq.8), it can be easily shown that:

$$
\rho=\frac{\mu(1-\alpha)}{\alpha} \frac{w_{S} S}{w_{N}}+g_{w_{N}}-g_{A},
$$

from which we can conclude that (with $g_{A}$ and $S$ constant) $g_{w_{N}}$ is constant if and only if $\frac{w_{S}}{w_{N}}$ is constant (if and only if $g_{w_{N}}=g_{w_{S}}$ ). We can now state the following:

Proposition 2 In the long run equilibrium, the output growth rate $\left(g_{Y}\right)$ equals the growth rate of the two wages (respectively $g_{w_{N}}$ and $g_{w_{S}}$ ). In other words: $g_{Y}=g_{w_{N}}=g_{w_{S}}$. In addition, it is true that $\omega, N$ and $S$ are all constant.

Using Eq. 20 and the fact that $g_{A}=\mu N$, the output growth rate is:

$$
g_{Y}=\mu \gamma \phi(\alpha) N
$$

Proposition 3 For a given employment level in the research sector $(N)$, Eq. 23 implies that the aggregate growth rate depends positively on: 1) the productivity of the research workers $(\mu)$; 2) the level of the returns to scale in the final output sector $(\gamma)$; 3) the monopoly power enjoyed by intermediate firms $\left(\frac{1}{\alpha}\right)$.

Obviously, the growth rate also depends on the employment of research sector. In order to find out the equilibrium value of $N$, since $g_{w_{N}}=g_{Y}$, first of all let us rewrite Eq. 22 as:

$$
\rho=\frac{\mu(1-\alpha)}{\alpha} \frac{w_{S} S}{w_{N}}+g_{Y}-g_{A}
$$


Making use of Eq. 23 and the fact that $\omega \equiv \frac{w_{N}}{w_{S}}$ and $g_{A}=\mu N$, after some simple algebraic manipulations we define the labour demand schedule of the research sector:

$$
N=\frac{\alpha}{\alpha-\gamma(1-\alpha)}\left(\phi(\alpha) \frac{S}{\omega}-\frac{\rho}{\mu}\right)
$$

Plogging Eq. 13 into the previous one, this becomes:

$$
N=\frac{1}{1-\gamma \phi(\alpha)}\left[\phi(\alpha) \frac{1}{\omega}(\alpha G)^{\frac{1}{1-\gamma}}-\frac{\rho}{\mu}\right]
$$

For Eq. 24 to be economically meaningful, the term in brackets must be positive ${ }^{12}$. This implies that the inequality index has to be not too high $\left.\left(\omega<\frac{\mu}{\rho}\left[\phi(\alpha)(\alpha G)^{\frac{1}{1-\gamma}}\right)\right]\right)$

The steady state equilibrium is at the intersection of the wage setting function (Eq. 7) with the labour demand schedule of the research sector (Eq. 24).

In steady-state (when $g_{Y}=\mu \gamma \phi(\alpha) N$ ) the relative wage setting function (Eq. 7) becomes:

$$
\omega=\frac{\bar{q}}{\bar{q}-\rho+\mu \gamma \phi(\alpha) N-b \frac{1}{1-N}}
$$

Since in Eq. 25 the growth rate $g$ has been endogenised, the wage setting function is decreasing in $N$ if $N<1-\sqrt{\frac{\alpha b}{\mu \gamma(1-\alpha)}}$. When this condition holds, the negative effect of growth rate on wage inequality prevails. For higher $N$, the wage setting function is increasing in $N$ since the efficiency premium becomes higher and higher, the higher the number of reserch workers. Finally, when $\bar{q}-\rho>b$, the wage setting function displays a vertical asymptote for values of $N$ strictly lower than 1 .

\section{Market Power, Unemployment, Inequality and Growth}

In order to study the relationship between competition and growth within the present framework, first of all we should be particularly clear on what we

\footnotetext{
${ }^{12}$ Under the condition $\gamma<\alpha$, the term outside the brackets is positive for sure. Recall that $\gamma<\alpha$ makes the profit function of a generic intermediate firm decreasing with respect to the number of existing producers $(A)$.
} 
mean by (imperfect) competition and where the mark-up measure (we are going to use in the remainder of the paper) comes from. Indeed, as already pointed out by Aghion and Howitt (1997, p. 284) and Benassy (1998), due to the hypotheses of Dixit-Stiglitz (1977) technology in the downstream sector and the absence of any form of strategic interaction among producers in the intermediate sector, the natural measure of the degree of competition is, in this class of models, the parameter $\alpha$ (and not the number of firms operating in capital goods manufacturing). In fact, the higher $\alpha$, the higher the elasticity of substitution between two generic intermediate inputs (equal to $\left.\frac{1}{1-\alpha}\right)$. This means that they become more and more alike when $\alpha$ grows and, accordingly, the price elasticity of the derived demand curve faced by a local monopolist (equal, again, to $\frac{1}{1-\alpha}$ ) tends to be infinitely large when $\alpha$ tends to one. In a word, the "toughness" of competition in the intermediate sector is strictly and positively depending on the level of $\alpha$. Conversely, the inverse of $\alpha$, can be viewed as a proxy for how uncompetitive the sector is. Along these lines, a recent paper of Van De Klundert and Smulders (1997), compares, within an endogenous growth model, the "toughness" of Bertrand versus Cournot competition explicitely taking into account the perceived price-demand elasticity. They conclude that in an oligopolistic set-up: "...price competition à la Bertrand is tougher than quantity competition à la Cournot because the former results...in higher elasticity and lower profit margins set by firms" (p.108). Sutton (1991) also points out that, for a given number of incumbents in the market, the lower the markup coefficient (in our case $\frac{1}{\alpha}$ ), the stronger the competition. Therefore, in what follows $\frac{1}{\alpha}$ will represent the key variable in measuring the level of mark-up and (imperfect) competition in the intermediate goods production.

\subsection{Analitical results}

Steady state analysis is based on figure 4.1 which describes the wage setting function (wsf) (Eq. 25) and the labour demand curve (24) in the plane of the employment level in the R\&D sector, $N$ (x-axis) and the disparity index, $\omega$ (y-axis). The dotted lines are the same curves for higher $\alpha$.

Proposition 4 When market power decreases $(\Delta \alpha>0)$ :

1. the wsf shifts upwards, whereas the vertical intercept does not change.

2. the labour demand function shifts to the left.

3. employment in R\&D decreases. 
Figure 1: Wage setting and R\&D labour demand functions for different $\alpha$ (dotted lines are drawn for higher values of $\alpha$ )

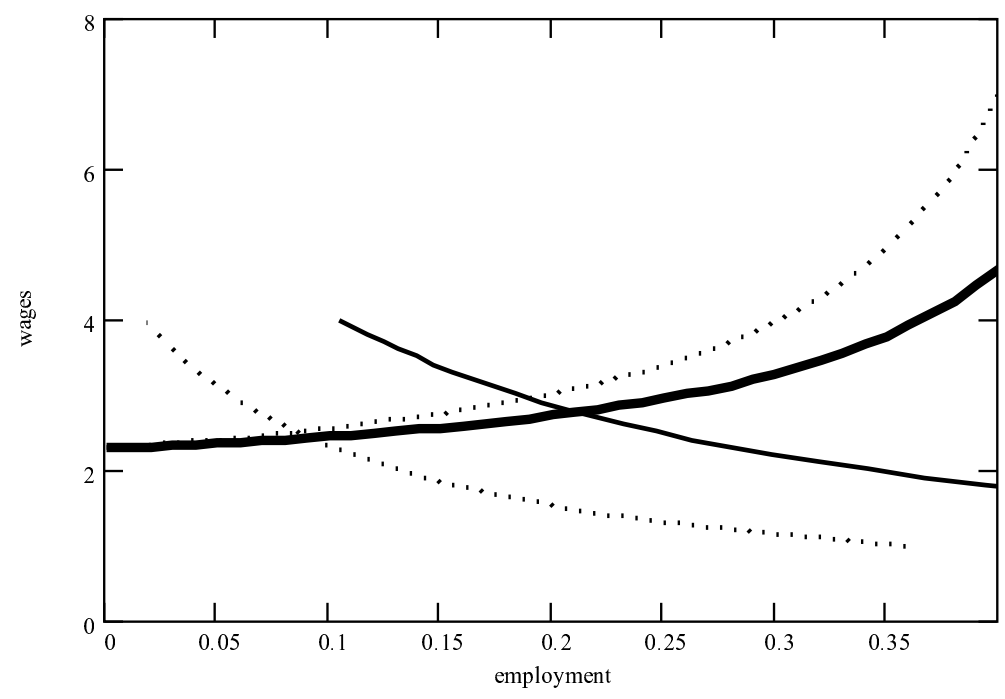

Proof 4 The proof of the first part of proposition 4 is easy. Deriving Eq. 25 with respect to $\alpha$, for a given $N$, we obtain $\frac{\partial \omega}{\partial \alpha}>0$. Moreover when $N=0$, Eq. 25 is always equal to $\omega=\frac{\bar{q}}{\bar{q}-\rho-b}$ for each mark-up size.

The proof of the second part of the proposition is less obvious. Let us consider first Eq. 24:

$$
N=\frac{1}{1-\gamma \phi(\alpha)}\left[\phi(\alpha) \frac{1}{\omega} S(\alpha)-\frac{\rho}{\mu}\right]
$$

Deriving $N$ with respect to a for given $\omega$, we obtain:

$$
\frac{\partial N}{\partial \alpha}=\frac{S(\alpha)}{1-\gamma \phi(\alpha)} \frac{1}{\omega}\left[\frac{\gamma \phi_{\alpha}^{\prime}}{1-\gamma \phi(\alpha)}\left(\phi(\alpha)-\frac{\rho}{\mu} \frac{\omega}{S(\alpha)}\right)+\phi_{\alpha}^{\prime}+\frac{1}{1-\gamma} \frac{\phi(\alpha)}{\alpha}\right]
$$

or

$$
\frac{\partial N}{\partial \alpha}=\frac{1}{1-\gamma \phi(\alpha)} \frac{S(\alpha)}{\omega}\left[\frac{\gamma-\alpha}{(1-\gamma) \alpha^{2}}+\frac{\gamma \phi_{\alpha}^{\prime}}{1-\gamma \phi(\alpha)}\left(\phi(\alpha)-\frac{\rho}{\mu} \frac{\omega}{S(\alpha)}\right)\right]
$$

The sign of Eq. 27 depends on the sign of the term in square brackets, which is negative. In fact: $\frac{\gamma-\alpha}{(1-\gamma) \alpha^{2}}<0$ since $\gamma<\alpha$. Moreover, to have positive values of the R\&D employment, from 26 we obtain:

$$
\phi(\alpha)>\frac{\rho}{\mu} \frac{\omega}{S(\alpha)}
$$


and finally:

$$
\frac{\gamma \phi_{\alpha}^{\prime}}{1-\gamma \phi(\alpha)}\left(\phi(\alpha)-\frac{\rho}{\mu} \frac{\omega}{S(\alpha)}\right)<0
$$

Therefore $\frac{\partial N}{\partial \alpha}<0$.

The last part of proposition 4 is a consequence of the first two: if the labour demand function moves left and the wage setting function up, then employment must decrease.

On these bases, we may conclude that when market power in the intermediate sector increases:

1. R\&D employment increases (proposition 4);

2. the growth rate increases (Eq. 23);

3. employment in the intermediate sector decreases (Eq. 18);

4. total employment may increase or decrease depending on the result of job creation in R\&D and job destruction in the intermediate sector. It is not possible to define analitically the sign of total employment change due to an increase in market power;

5. wage inequality $(\omega)$ may increase or decrease as well. In fact from 25 we obtain:

$$
\frac{d w}{d \alpha}=\left(-\mu \gamma\left[\phi_{\alpha}^{\prime} N(\alpha)+\phi(\alpha) N_{\alpha}^{\prime}\right]+\frac{b N_{\alpha}^{\prime}}{(1-N(\alpha))^{2}}\right)\left(\frac{\omega}{q}\right)^{\frac{1}{2}}
$$

We know that $\phi_{\alpha}^{\prime}$ and $N_{\alpha}^{\prime}$ are negative. This means that the sign of the first term is positive. On the contrary, the second term is always negative. In sum, it is not possible to determine the sign of the relation between inequality and market power. In any case, if $b$ is near to 0 , then the wage inequality is increasing with $\alpha$ (it is negatively correlated to market power). Thus, for low turnover values (b) wage inequality is decreasing with market power and growth .

These are the main analytical conclusions concerning the relation between market power and the main macro-variables of the model . To clarify the nature of these relations and to derive further information, we propose some numerical simulations. 


\subsection{The relationships among $\alpha, u, \omega$ from numerical sim- ulations}

In this section we use numerical simulations in order to obtain a more precise information about the relationships among market power, unemployment rate and wage inequality.

First notice that, since some of the parameters of our model represent probabilities $(b, q)$, whereas some others are constrained $(\gamma<1, \alpha>\gamma)$ it is not difficult to set a range for their plausible values. Furthermore, the simulations we propose are built in such a way to obtain "realistic" values for the unemployment rate, the wage inequality and the growth rate.

We define the parameters values and simulate the model as follows:

- we set $\rho=0.04$ and $\mu=1$ throghout all the simulations;

- we assume uniform distributions for $\gamma$ and $b$, precisely: $0.2 \leq \gamma \leq 0.5$ and $0.01 \leq b \leq 0.25$

- we set $\alpha=\gamma+(1-\gamma) a 0$, where $a 0$ is uniformly distributed between 0 and 1 (this condition implies that intermediate firms profits are decreasing in the number of firms). This formulation also satisfies the constraints $0<\gamma<\alpha<1$;

- we set $\bar{q}=(b+\rho+0.3)+[1-(b+\rho)] a 1$, were $a 1$ is uniformly distributed between 0 and 1 , this condition is necessary in order to have a positive value of $\omega$ for each $N>0$ (see Eq. 7);

- we set $G=a 2 \frac{1-\alpha}{\alpha}+1$, were $a 2$ is uniformly distributed between 0 and 1, that is a necessary condition in order to have $S<1$ (see Eq. 13 and the definition of $G$ );

- we derive analitycally $N^{*}$ from Eqs. 26 and 25;

- we get random vectors for $\gamma, q, a 0 a 1, a 2$;

- we simulate 100000 times the model, obtainining numerical values for $N^{*}, S^{*}, \omega^{*}, g^{*}$

- in each simulation we compute the value of $\alpha_{1}=\alpha+\varepsilon$, with $\varepsilon$ infinetely small;

- we select all results for which $N^{*}, S^{*}, N^{*}+S^{*}$ are in the range $(0 ; 1)$ and $\omega>1$ and discard all the others. We remain with 26037 valid cases. 
Table 1 presents the minimum, maximum, average and standard deviation of parameters coming from selected simulation:

Table 1: Parameters values

\begin{tabular}{|c|c|c|c|c|}
\hline parameters & minimum & maximum & average & Std dev. \\
\hline$\alpha$ & 0.447 & 0.959 & 0.806 & 0.108 \\
$\gamma$ & 0.200 & 0.500 & 0.358 & 0.086 \\
$\mathrm{~b}$ & 0.010 & 0.250 & 0.151 & 0.064 \\
$\bar{q}$ & 0.356 & 1.300 & 0.885 & 0.236 \\
\hline
\end{tabular}

Figure 2 presents the distributions of the unemployment rate and wage inequality obtained from the numerical simulations. The results show that the average is $9.7 \%$ for the unemployment rate and 1.2 for the wage inequality. The simulated growth rate has an hyperbolic distribution whose average is $1.7 \%$.

Figure 2: Unemployment distribution-Wage inequality distribution
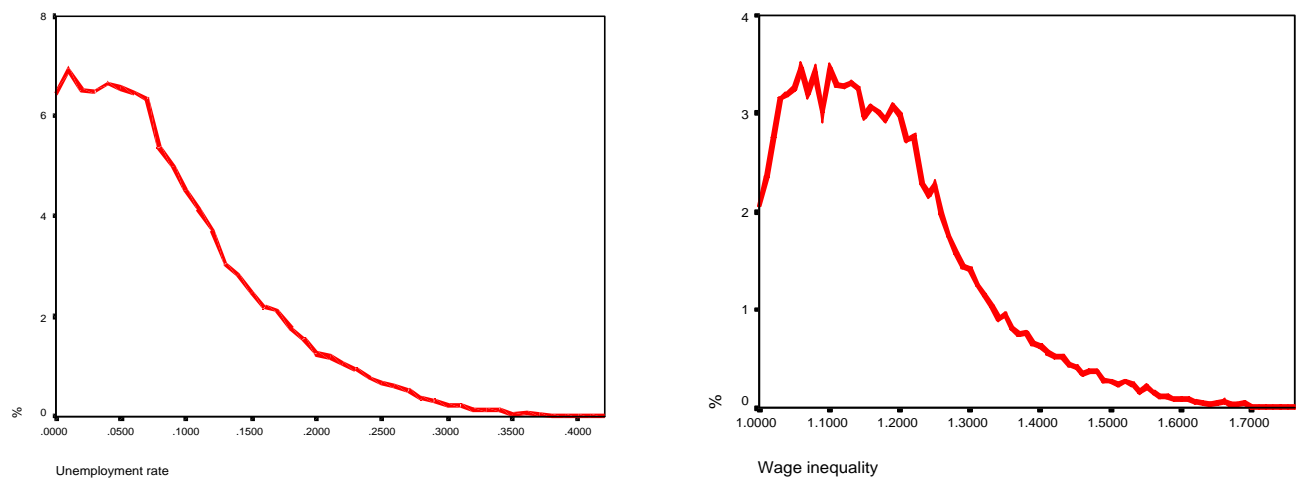

The next proposition summarises the main results obtained from our simulations:

Proposition 5 An increase in market power leads to an increase in unemployment in $93.6 \%$ of cases and to a reduction of wage inequality in $97.4 \%$ of cases.

Figures 3 and 4 plot the market power (on the horizontal axe) with respect to the unemployment rate and wage inequality, respectively. Each point 
represents the result of a simulation. The points (and the areas) colored in black represent the cases where the previous proposition do not apply (respectively, $6.4 \%$ and $2.6 \%$ of cases) ${ }^{13}$.

Hence we can conclude that:

Proposition 6 The lower product market competition, the higher the probability that a further increase in the monopolistic power leads to a reduction in unemployment and to an increase in the wage inequality.

Figure 3: Unemployment rate with respect to market power

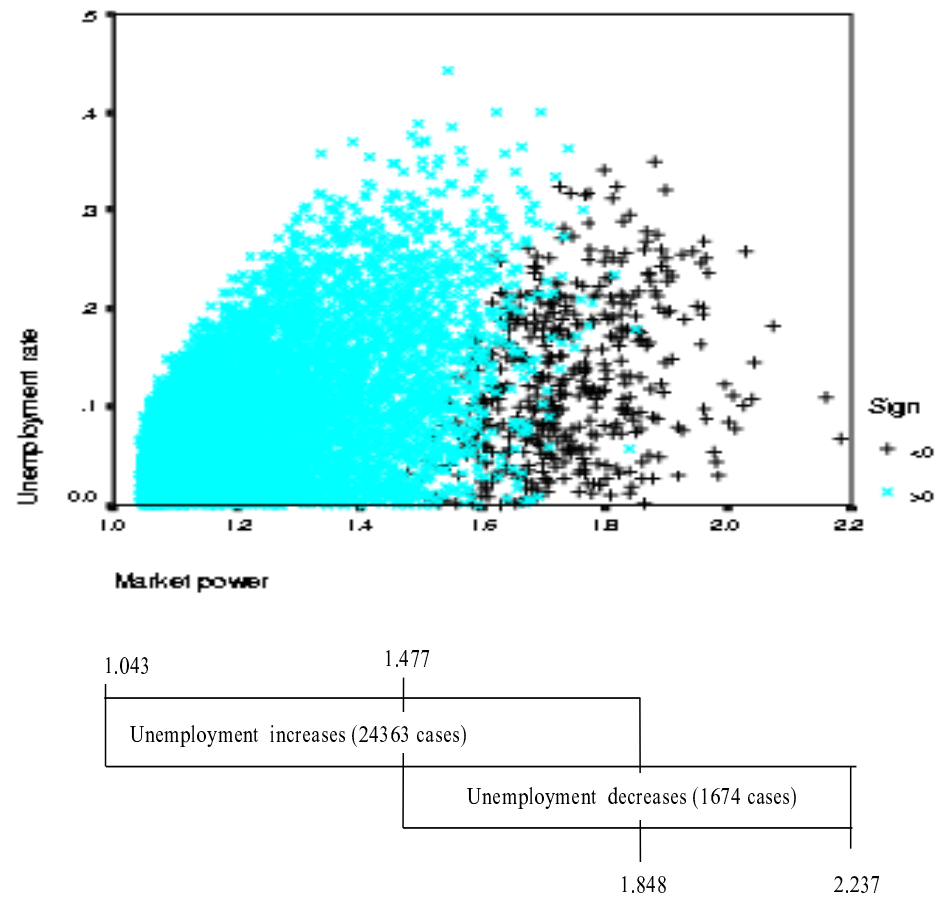

Figure 3 shows clearly that, when market power is lower than a given level (around 1.5) all simulations display an increase in unemployment when market power increases further. The sign of the relationship reverses, but not in all cases, for higher $\alpha$. Only if $\frac{1}{\alpha}$ is above 1.85 we obtain a decrease in unemployment when market power increases.

\footnotetext{
${ }^{13}$ Recall that, for each simulation, taking as given all the other parameters, we have two results: the first refers to the value of the unemployment rate and wage inequality for a random $\alpha$, and the second refers to the same variables as before for an $\alpha_{1}=\alpha+\varepsilon$. So, in each simulation, we know the sign of the relationship between variations in the monopoly power and the correspondant variations in the other two variables mentioned above.
} 
Figure 4: Wage inequality with respect to market power

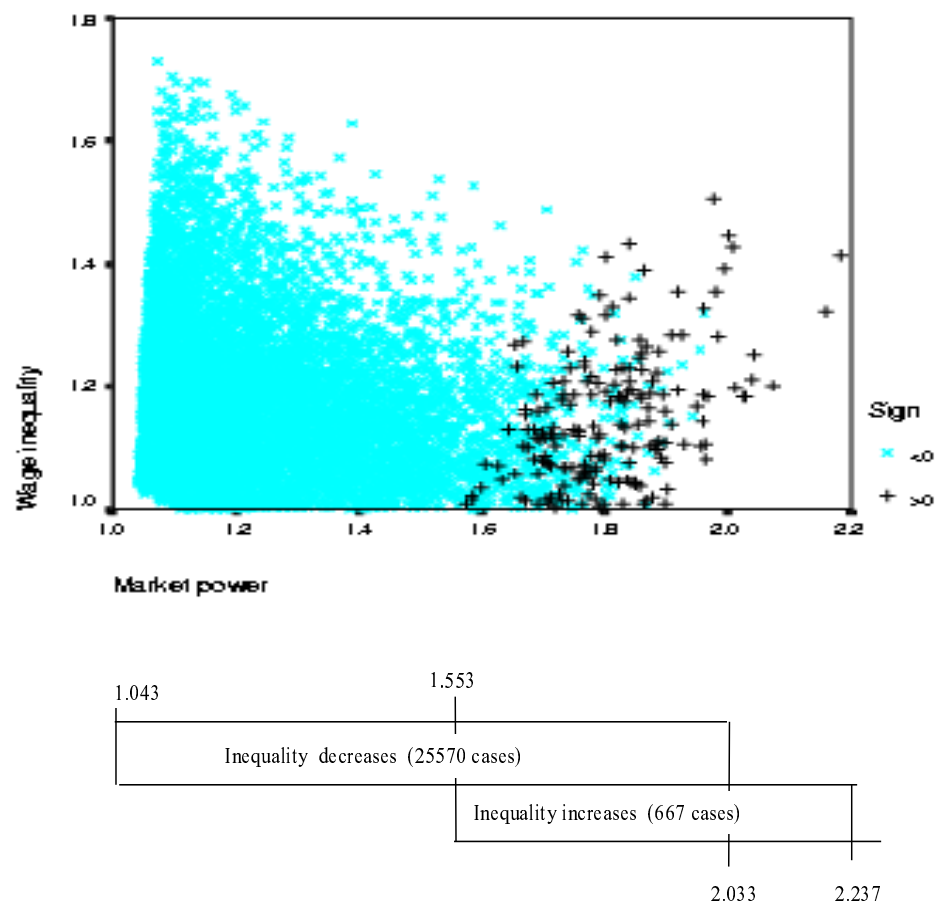

Figure 4 shows that a positive relationship between market power and wage inequality may exist only when the market power is higher than 1.55. Otherwise, an increase in $\frac{1}{\alpha}$ gives rise to a decrease in wage inequality.

The graphs reported in figure 5 show the dynamics of the variables of interest with respect to 'realistic' values of parameters. In particular, the first graph shows the wage inequality, the second the rate of growth, the third the sectoral distribution of employment and the last the unemployment rate as a function of $\frac{1}{\alpha}$. Generally speaking, most of our simulations confirm the situation described in figure 5: the higher the market power, the lower the wage disparity, the higher the growth and unemployment rates. Employment in the $\mathrm{R} \& \mathrm{D}$ sector is increasing, whereas it is decreasing in the intermediate sector.

\section{Concluding Remarks}

In models dealing with unemployment, the presence of efficiency wages is a common hypothesis. In this paper we incorporate this hypothesis within an 
Figure 5: Model's variables and market power
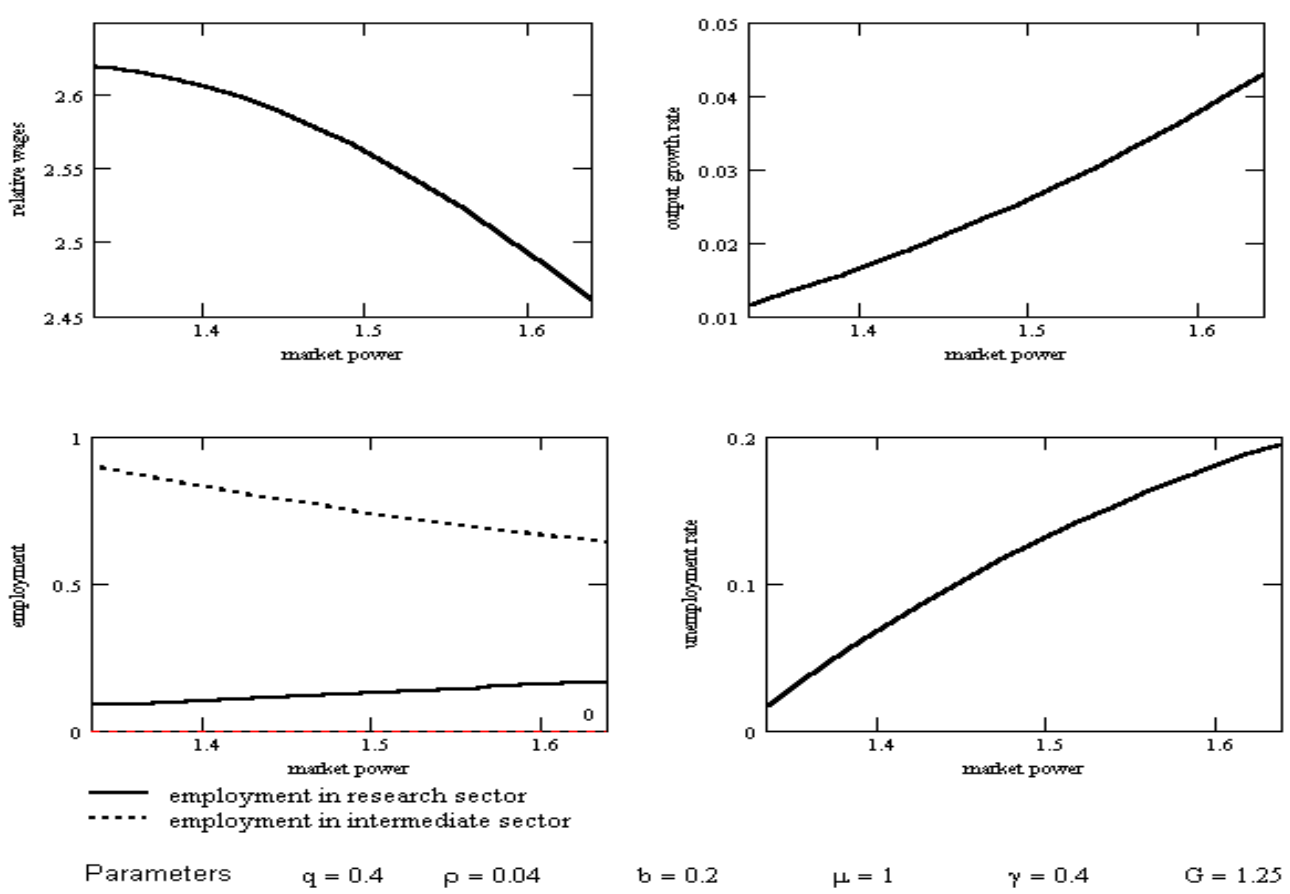

endogenous growth model where R\&D is the engine of growth. Our aim is to study how product market competition in the intermediate sector impacts on the sectoral employment share, the unemployment rate, wage inequality and aggregate growth.

As in several endogenous growth models (i.e. Bucci 1998), we find that increasing market power makes the growth rate increase as well. However, unlike these models (displaying full employment), in our paper labour market is segmented and unemployment arises due to the efficiency wage hypothesis. In this respect we find that a higher market power creates new jobs in the $\mathrm{R} \& \mathrm{D}$ sector and destroys them in the intermediate inputs one. The overall effect is not predictable analitically, but looking at numerous numerical simulations carried out, job destruction seems to prevail on job creation. In other words market power is positively correlated with unemployment.

Due to the payment of efficiency wages in the research sector but not in the intermediate one, wage inequality is a natural result. The sign of the relationship between wage inequality and growth can not be defined analitycally. However, from numerical simulations it emerges that market power is negatively correlated with wage inequality. For high values of market 
power the relation between market power and unemployment/inequality may be reversed.

In sum, an higher growth rate, that depends positively on firms market power, tends to destroy jobs and to reduce wage inequality. This result would confirm the main conclusion of Caballero and Hammour (1998), according to which a situation where growth and unemployment both increase is possible. 


\section{References}

[1] P. Aghion and P. Howitt. A model of growth through creative destruction. Econometrica, 60(2):323-51, 1992.

[2] P. Aghion and P. Howitt. Growth and unemployment. Review of Economic Studies, 61(3):477-94, 1994.

[3] P. Aghion and P. Howitt. A Schumpeterian Perspective on Growth and Competition, pages 279-317. Volume II of Kreps and Wallis [14], 1997.

[4] C.R. Bean and C. Pissarides. Unemployment, consumption and growth. European Economic Review, 37(4):837-54, 1993.

[5] J.P Benassy. Is there always too little research in endogenous growth with expanding product variety? European Economic Review, 42(1):6169, 1998.

[6] A. Bucci. Market power and growth in a schumpeterian framework of innovation. Discussion Paper Universitè catholique de Louvain (IRES Discussion Papers Series), n.9824, 1998.

[7] R.J. Caballero. Unemployment, consumption and growth: Comments. European Economic Review, 37(4):855-59, 1993.

[8] R.J. Caballero and M.L. Hammour. Jobless growth: Appropriability, factor substitution, and unemployment. Carnegie Rochester Conference Series on Public Policy, 48(0):51-94, 1998.

[9] P. Cahuc and H. Zajdela. Comment expliquer le dualisme du marche du travail a partir de comportements rationnels? Revue Economique, 42(3):469-91, May 1991.

[10] A. Dixit and J. Stiglitz. Monopolistic competition and optimum product diversity. American Economic Review, 67(3):297-308, 1977.

[11] F. Fiorillo and S. Staffolani. To redistribute or not? unemployment benefit, workfare and citizen's income in a dual labour market. Quaderni di Ricerca, Dipartimento di Economia di Ancona, 128, marzo 2000.

[12] E. Grossman and G.M. Helpman. Innovation and growth in the global economy. MIT press, 1991.

[13] T. Van De Klundert and S. Smulders. Growth, competition and welfare. Scandinavian Journal of Economics, 99(1):99-118, 1997. 
[14] D.M. Kreps and K.F. Wallis (eds.). Advances in Economics and Econometrics: Theory and Applications, volume II. Cambridge University Press, 1997.

[15] R. Layard, S. Nickell, and R. Jackman. Unemployment: Macroeconomic performance and the labour market. Oxford University Press, 1991.

[16] R. Mendez. Creative destruction and the rise of inequality. EUREQUA, Universitè de Paris 1, Paris France, 1999.

[17] F. De Palma. Hétérogénéité des travailleurs, dualism et salarire d'efficience. Working Paper, Université Louis Pasteur, BETA-Theme, April 2000.

[18] A. Perrot and A. Zylberberg. Salaire d'efficience et dualisme du marche du travail. Revenue Economique, 40(1):5-20, 1989.

[19] P. Romer. Endogenous technological change. Journal of Political Economy, 98(5):71-102, 1990.

[20] A. Van Schaik and H. De Groot. Unemployment and endogenous growth. Labour, 12(1):189-219, 1998.

[21] C. Shapiro and J. Stiglizt. Equilibrium unemployment as a worker discipline device. American Economic Review, 74(3):433-444, 1984.

[22] J. Sutton. Sunk Costs and Market Structure: Price Competition, Advertising and the Evolution of Concentration. Cambridge, MA, MIT Press, 1991. 